\title{
Grounding Grid Performance of SubStation in Two LAYER SOIL - A PARAMETRIC ANALYSIS
}

\author{
M.G. Unde ${ }^{1}$, B.E. Kushare ${ }^{2}$ \\ ${ }^{1}$ Professor \& Head, Department of Electrical Engineering, \\ Pad. Dr. Vithalrao Vikhe Patil College of Engineering, Ahmednagar, India \\ ${ }^{2}$ Professor \& Head, Department of Electrical Engineering, \\ K.K.W.I.E.E.R. College of Engineering, Nasik, India
}

\begin{abstract}
During ground faults, fault current flows in the ground which results in potential gradient and ground potential rise (GPR). The potential gradient affects the safety of operating person due to step and touch voltage and GPR affects the insulation of protective devices and control cables. The potential gradient and GPR are the functions of ground electrode geometry. In this paper, performance assessment and analysis of grounding grid is carried out for different types of grid electrodes with two layer soil model for both positive and negative reflection factor K. The simulation is carried out to evaluate grounding grid performance indices such as Ground resistance, Mesh voltage, Step voltage, Ground Potential Rise. The various parameters used for the simulation are, depth of ground grid, Number of meshes and length of ground rods. The results are tabulated, and discussed. The SES Autogrid Pro grounding software, Canada is used for the analysis.
\end{abstract}

\section{KEYWORDS}

Grounding grid, GPR, potential gradient, Mesh voltage, Step voltage

\section{INTRODUCTION}

The main objectives of design of the substation grounding grid under normal as well as fault conditions are-

- To ensure that person in the vicinity of grounded object is not exposed to electric shock.

- To provide a low impedance path to carry the fault current into ground without exceeding any operating \& equipment limits.

- During fault condition, continuity of the service should not be affected.[1-3]

Grounding grid performance indices such as ground resistance, touch voltage, step voltage, surface potential, ground potential rise depends on soil structure and grid configuration [1]. Grid configuration may be equally or unequally spaced grid conductors with or without ground rods. Soil structure may be uniform, two layer, multi layer, vertical layer, cylindrical, spherical, heterogeneous etc. since; the soil resistivity varies horizontally as well as vertically depending on soil stratifications [2]. Seasonal variations may occur in the soil resistivity due to varying weather conditions. However, resistivity variation with climatic condition is limited to few feet only at the surface of the earth, keeping lower part of the resistivity practically constant [3,4,5].

The uniform and two layer soil structure for substation ground grid design is mostly used in India [4],[5].The comparison between theoretical values and experimental values for various types of grounding grid performance at fixed depth is carried out [5],[6]. Dawalibi and Mukhedkar had carried 
out parametric analysis of grounding grid in uniform and two layer soil [7]. Dawalibi et.al compared the measured and calculated values of current densities of grounding grid [7],[1]. Analysis of surface potential and current densities in multilayer soil is available in the literature [8,9,10].In this paper, grounding grid performance indices such as Ground resistance( $\mathrm{Rg}$ ), Mesh voltage (Em), Step voltage(Es), Ground potential rise(GPR) are carried out for various types of grid configurations in two layer soil structure for both positive and negative refection factor $K$.

$$
\text { where } \quad K=\frac{\rho_{2}-\rho_{1}}{\rho_{2}+\rho_{1}} \quad \text {----Reflection factor. }
$$

$\rho_{1}=$ Resistivity of top layer up to certain definite depth.

$\rho_{2}=$ Resistivity of bottom layer up to infinite depth.

Case: 1 when $\rho_{1}<\rho_{2}$--- positive value of $K$

Case: 2 when $\rho_{1}>\rho_{2} \quad \ldots$ negative value of $K$

The simulation is carried out by-

- Varying grid depth

- Increasing number of meshes

- Adding ground rods of varying length.

In particular, we focus our attention on the effect of grid structure variations on step voltage, touch (mesh) voltage, grid resistance and ground potential rise which affects the safety of person and reliability of controlling devices respectively.

\section{Simulation of Grounding Grids}

In this study, various grounding grid considered for this analysis are as follows.

$\mathrm{S}_{1}=20 \mathrm{~m} \times 20 \mathrm{~m}$ square grid $=01 \mathrm{mesh}$

$\mathrm{S}_{2}=20 \mathrm{~m} \times 20 \mathrm{~m}$ square grid $=04$ meshes

$\mathrm{S}_{3}=20 \mathrm{~m} \times 20 \mathrm{~m}$ square grid $=16$ meshes

$\mathrm{S}_{4}=20 \mathrm{~m} \times 20 \mathrm{~m}$ square grid $=64$ meshes

$\mathrm{S}_{5}=20 \mathrm{~m} \times 20 \mathrm{~m}$ square grid $=100$ meshes

All the square grids are made of linear conductors with radius $0.01 \mathrm{~m}$ and uniformly spaced. The depth of burial of grid is kept varying from $0.5 \mathrm{~m}$ to $100 \mathrm{~m}$. The fault current injected into the grounding grid is 1000A. The two layer soil model having upper layer resistivity $\rho_{1}=36 \Omega \mathrm{m}$ with layer depth $\mathrm{h}=6.4 \mathrm{~m}$ and lower layer resistivity $\rho_{2}=342 \Omega \mathrm{m}$ up to infinite depth. The study have been carried out for both positive and negative values of $K$

\section{EFFECT OF DEPTH OF GROUND GRID}

The grid depth is varied from $0.5 \mathrm{~m}$ to $100 \mathrm{~m}$ at a certain intervals and corresponding effect on mesh voltage, step voltage, grid resistance, and ground potential rise are analyzed for grounding grids $S_{1}$, $\mathrm{S}_{2}, \mathrm{~S}_{3}, \mathrm{~S}_{4}$, and $\mathrm{S}_{5}$ using SES AUTOGRID PRO software are shown in table 1-4 for case 1 and case 2. The grid current injected for each type of grid is $1000 \mathrm{~A}$.

\subsection{Mesh Voltage}

Once field data ie area of grounding grid is fixed, the mesh voltage depends on resistivity of the soil, conductor spacing, number of meshes, current per meter length of the conductor and depth at which grid is buried. [1],[3],[11].The mesh voltage is plotted against depth of grid burial for grid type $S_{1}, S_{2}$, $\mathrm{S}_{3}$ and $\mathrm{S}_{4}$ is shown in Figs. 1 and 2 for cases 1 and 2 respectively. For the same grid depth, at $0.5 \mathrm{~m}$, mesh voltage decreases as number of meshes increases.

For positive value of $K$ ie case 1, as grid depth increases, mesh voltage increases slowly up to the top layer height. However, at the boundary of the two soil layer, mesh voltage increases abruptly and there after continuingly increases at low rate due to presence of high resistivity layer beneath the low resistivity layer. For negative value of $K$ ie case 2, phenomenon is reversed. 
International Journal of Engineering Sciences \& Emerging Technologies, Feb 2012. ISSN: 2231 - 6604 doi: 10.7323/ijeset/v1_i2_8 Volume 1, Issue 2, pp: 69-76 OIJESET

Table 1 Variation of mesh voltage with grid depth. Case: 1

\begin{tabular}{|l|l|l|l|l|}
\hline $\begin{array}{l}\text { Grid } \\
\text { depth } \\
(\mathrm{m})\end{array}$ & $\begin{array}{l}\mathrm{S}_{1} \\
\text { Em (V) }\end{array}$ & $\begin{array}{l}\mathrm{S}_{2} \\
\text { Em }(\mathrm{V})\end{array}$ & $\begin{array}{l}\mathrm{S}_{3} \\
\mathrm{Em}(\mathrm{V})\end{array}$ & $\begin{array}{l}\mathrm{S}_{4} \\
\text { Em }(\mathrm{V})\end{array}$ \\
\hline 0.5 & 471.93 & 286.78 & 193.58 & 141.60 \\
\hline 2 & 398.92 & 331.11 & 263.56 & 210.18 \\
\hline 4 & 476.48 & 390.46 & 317.67 & 267.16 \\
\hline 6.4 & 845.72 & 650.24 & 509.57 & 423.90 \\
\hline 8 & 4282.1 & 3088.9 & 2247.7 & 2310.0 \\
\hline 10 & 4737.4 & 3520.0 & 2708.9 & 2744.4 \\
\hline 12 & 5000.8 & 3802.2 & 3007.5 & 2991.4 \\
\hline 15 & 5262.1 & 4085.2 & 3303.7 & 3201.5 \\
\hline 20 & 5527.3 & 4366.5 & 3892.1 & 3397.8 \\
\hline 50 & 6000.3 & 4865.7 & 4100.7 & 3703.1 \\
\hline 100 & 6198.3 & 5050.8 & 4278.7 & 3844.6 \\
\hline
\end{tabular}

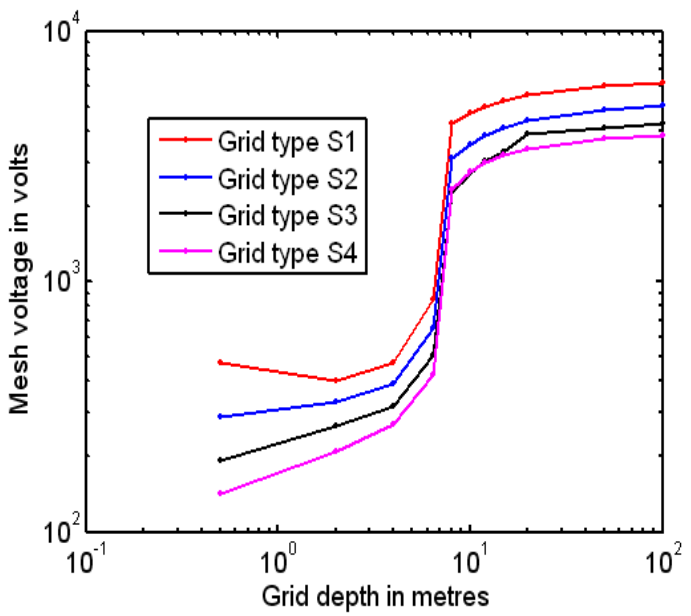

Fig. 1 Variation of mesh voltage with grid depth for all types of grids. case : 1
Table 2. Variation of mesh voltage with grid depth. Case: 2

\begin{tabular}{|l|l|l|l|l|}
\hline $\begin{array}{l}\text { Grid } \\
\text { depth } \\
(\mathrm{m})\end{array}$ & $\begin{array}{l}\mathrm{S}_{1} \\
\operatorname{Em}(\mathrm{V})\end{array}$ & $\begin{array}{l}\mathrm{S}_{2} \\
\operatorname{Em}(\mathrm{V})\end{array}$ & $\begin{array}{l}\mathrm{S}_{3} \\
\operatorname{Em}(\mathrm{V})\end{array}$ & $\begin{array}{l}\mathrm{S}_{4} \\
\operatorname{Em}(\mathrm{V})\end{array}$ \\
\hline 0.5 & 5295.6 & 2871.1 & 1524.4 & 944.85 \\
\hline 2 & 4368.5 & 2305.5 & 1684.4 & 1235.6 \\
\hline 4 & 3892.4 & 2448.0 & 1669.8 & 1204.1 \\
\hline 6.4 & 767.97 & 561.77 & 413.75 & 327.66 \\
\hline 8 & 472.00 & 360.00 & 282.22 & 217.91 \\
\hline 10 & 465.90 & 350.84 & 271.16 & 205.43 \\
\hline 12 & 471.45 & 352.13 & 271.00 & 206.95 \\
\hline 15 & 484.23 & 361.74 & 279.80 & 219.20 \\
\hline 20 & 507.51 & 383.74 & 301.79 & 246.39 \\
\hline 50 & 595.10 & 474.24 & 392.97 & 344.36 \\
\hline 100 & 637.90 & 517.44 & 436.44 & 389.19 \\
\hline
\end{tabular}

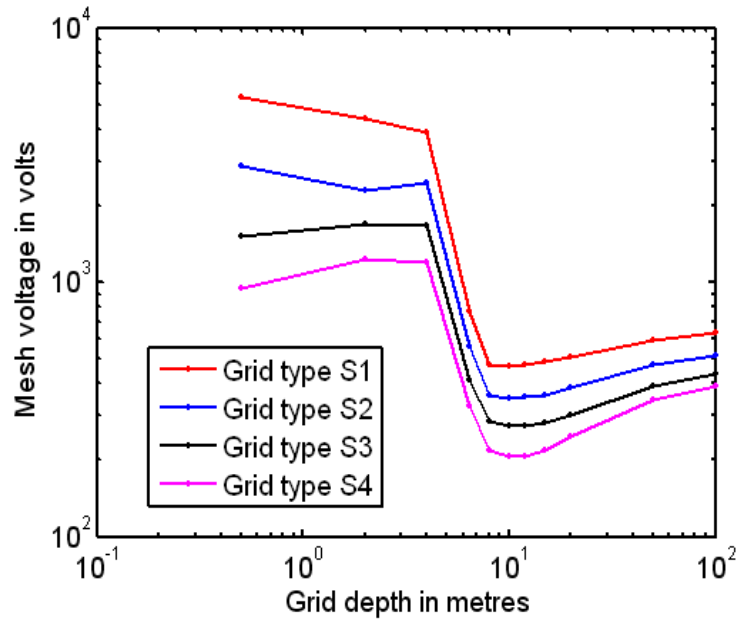

Fig. 2 Variation of mesh voltage with grid depth for all types of grids case: 2

\subsection{GPR and Grid Resistance}

Variation of GPR, mesh voltage and ground resistance with grid depth for $\mathrm{S}_{4}$ grid is plotted in figure 3 for both the cases. For shallow grid depth, GPR for case 1, is less as it is kept in low resistivity layer and is high for case 2 , as it lies in the high resistivity layer.

For case 2: GPR and ground resistance decreases continuously with depth of the grid. It is observed that there is sudden decrease in GPR and grid resistance at the boundary of two layers. Reverse happens in case 1 .

In both the cases, when the depth of the burial becomes more than equivalent radius of the grid area about $11 \mathrm{~m}$ for this grid, the decrease in GPR and grid resistance becomes almost constant as shown in Fig. 3 .In fact, resistance curve can be obtained simply dividing the GPR by grid current equal to 1000A. 
International Journal of Engineering Sciences \& Emerging Technologies, Feb 2012. ISSN: $2231-6604$ doi: $10.7323 /$ ijeset/v1_i2_8 Volume 1, Issue 2, pp: 69-76 OIJESET

Table 3. Variation of $\mathrm{Rg}$ and GPR with grid depth for $\mathrm{S}_{4}$

\begin{tabular}{|l|l|l|l|l|}
\hline $\begin{array}{c}\text { Grid } \\
\text { depth } \\
(\mathrm{m})\end{array}$ & \multicolumn{2}{|l|}{ case: 1} & \multicolumn{2}{|c|}{ case: } \\
\cline { 2 - 5 } & $\operatorname{Rg}(\Omega)$ & $\begin{array}{l}\text { GPR } \\
(\mathrm{V})\end{array}$ & $\operatorname{Rg}(\Omega)$ & GPR $(\mathrm{V})$ \\
\hline 0.5 & 2.000 & 2007.2 & 3.922 & 3922.4 \\
\hline 2 & 1.943 & 1942.8 & 3.176 & 3176.2 \\
\hline 4 & 1.922 & 1921.8 & 2.369 & 2369.2 \\
\hline 6.4 & 2.042 & 2041.1 & 0.824 & 824.16 \\
\hline 8 & 3.841 & 3841.3 & 0.671 & 671.14 \\
\hline 10 & 4.178 & 4178.5 & 0.614 & 614.20 \\
\hline 12 & 4.340 & 4340.0 & 0.578 & 578.52 \\
\hline 15 & 4.440 & 4439.1 & 0.545 & 545.00 \\
\hline 20 & 4.469 & 4469.2 & 0.514 & 514.13 \\
\hline 50 & 4.344 & 4344.3 & 0.464 & 464.28 \\
\hline 100 & 4.230 & 4234.2 & 0.449 & 448.83 \\
\hline
\end{tabular}

Table 4. Variation of step voltage with grid

\begin{tabular}{|l|l|l|}
\hline $\begin{array}{l}\text { Grid } \\
\text { depth } \\
(\mathrm{m})\end{array}$ & $\begin{array}{l}\text { case : 1 } \\
\text { Estep } \\
(\mathrm{V})\end{array}$ & $\begin{array}{l}\text { case:2 } \\
\text { Estep } \\
(\mathrm{V})\end{array}$ \\
\hline 0.5 & 91.35 & 570.17 \\
\hline 2 & 52.46 & 274.39 \\
\hline 4 & 38.72 & 142.47 \\
\hline 6.4 & 37.34 & 26.97 \\
\hline 8 & 35.23 & 20.00 \\
\hline 10 & 26.58 & 15.48 \\
\hline 12 & 20.71 & 12.15 \\
\hline 15 & 14.94 & 8.58 \\
\hline 20 & 9.23 & 5.00 \\
\hline 50 & 1.36 & 0.50 \\
\hline 100 & 0.25 & 0.64 \\
\hline
\end{tabular}

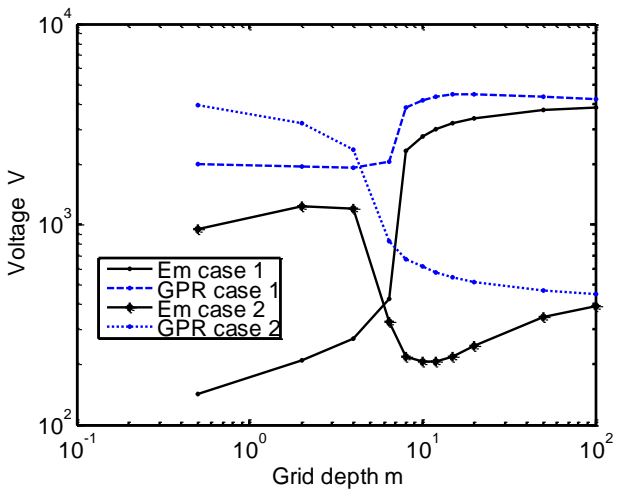

Fig. 3 GPR and mesh voltage with depth for $\mathrm{S}_{4}$

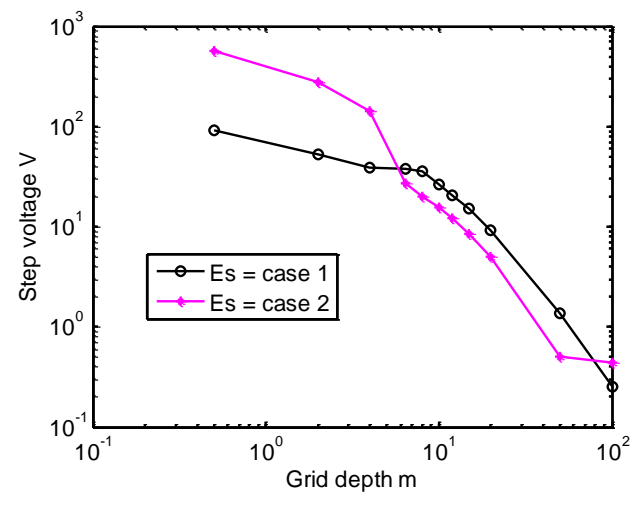

Fig. 4 Variation of step voltage with grid depth for $S_{4}$

\subsection{Step Voltage}

Step voltage is one of the important criterions for the safety of the person [12-13]. The maximum step voltage is assumed to occur over a distance of 1 meter diagonally outside the corner of the grid [1],[3]. Step voltage depends on grid geometry irregularity factor $\mathrm{Ki}$, spacing factor $\mathrm{Ks}$, grid depth and current per meter length of the conductor[2].The variation of step voltage against the grid burial depth and plot for both the cases are shown in table 4 and figure 4 respectively. For case 1 , rate of decrease in step voltage is high as compared to case 2.

\section{EFFECT OF INCREASING NuMber OF MESHES}

Grid type $S_{1}, S 2, S 3, S 4$ and $S_{5}$ are simulated. The depths of burial of all the grids are kept $0.5 \mathrm{~m}$ and current of $1000 \mathrm{~A}$ is injected into the grids. The effect on ground resistance, mesh voltage and GPR is tabulated in table 5 and 6.The mesh voltage and ground resistance is plotted against number of meshes as shown in figure 5 and 6.

\subsection{Ground Resistance}

Ground resistance of the substation primarily depends on soil resistivity, area available and grid configuration [1],[14-18]. In both the cases, ground resistance Rg decreases, when number of meshes is increased. However, the decrease in $\mathrm{Rg}$ in case 2 is noticeable i.e. $41.67 \%$, when number of meshes increased from 1 to 100, as low resistivity soil is beneath to high resistivity layer. In case 1 , it is only $10.72 \%$ i.e. remains almost constant 


\subsection{Mesh Voltage}

For case 1 , mesh voltage of one mesh grid is $21.09 \%$ of GPR and decreases to $6.35 \%$, when number of meshes are increased to 100 . In case 2 ; for one mesh grid, mesh voltage is $80.16 \%$ of GPR and decreased to $21.86 \%$. Effect on GPR is similar to as discussed in (4.1)

Table 5 Variation of mesh voltage and GPR with Number of meshes.

\begin{tabular}{|l|l|l|l|l|}
\hline $\begin{array}{l}\text { No. } \\
\begin{array}{l}\text { No.of } \\
\text { meshes }\end{array}\end{array}$ & \multicolumn{2}{|l|}{ case : 1 } & \multicolumn{2}{l|}{ case:2 } \\
\cline { 2 - 5 } & Em (V) & $\begin{array}{l}\text { GPR } \\
\text { (V) }\end{array}$ & Em(V) & GPR (V) \\
\hline 1 & 471.93 & 2238.2 & 5295.64 & 6606.0 \\
\hline 4 & 286.78 & 2124.0 & 2871.66 & 5193.1 \\
\hline 16 & 193.58 & 2050.1 & 1524.4 & 4357.8 \\
\hline 64 & 141.60 & 2007.2 & 944.85 & 3922.4 \\
\hline 100 & 126.86 & 1997.7 & 838.6 & 3834.9 \\
\hline
\end{tabular}

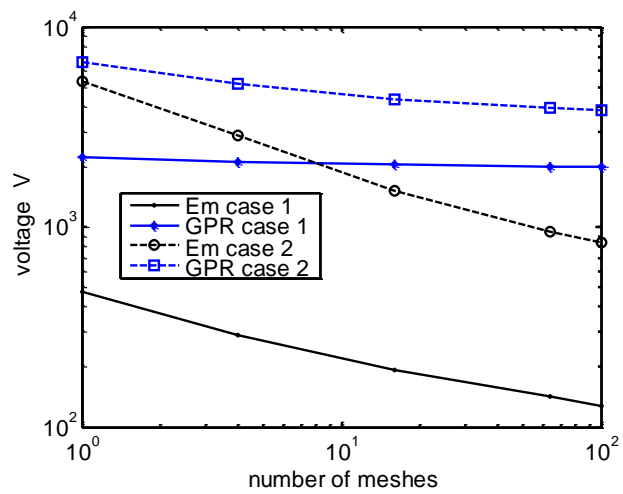

Fig. 5 Variation of mesh voltage and GPR with number of meshes.
Table 6. Variation of grid resistance with of number no. of meshes

\begin{tabular}{|l|l|l|}
\hline $\begin{array}{l}\text { No.of } \\
\text { meshes }\end{array}$ & $\begin{array}{l}\text { case:1 } \\
\operatorname{Rg}(\Omega)\end{array}$ & $\begin{array}{l}\text { case:2 } \\
\operatorname{Rg}(\Omega)\end{array}$ \\
\hline 1 & 2.238 & 6.606 \\
\hline 4 & 2.124 & 5.193 \\
\hline 16 & 2.050 & 4.358 \\
\hline 64 & 2.000 & 3.922 \\
\hline 100 & 1.998 & 3.835 \\
\hline
\end{tabular}

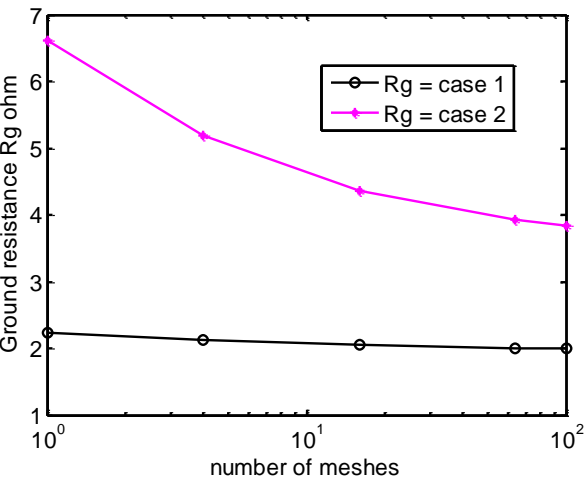

Fig. 6 Variation of grid resistance with number of meshes

\section{EFFEct OF Length OF GROUND Rod}

Grid type $\mathrm{S} 4$ is simulated for both the cases. The depth of burial is at $0.5 \mathrm{~m}$. The rod length is increased from 00 to $15 \mathrm{~m}$.The rods are placed on periphery and inside the grid judicially. The grid is shown in figure 8.The effect on mesh voltage and ground resistance are tabulated in table 7.The plots of mesh voltage Em and ground resistance Rg against rod length are shown in figure 8 and 9.

Table 7. Variation of grid resistance \& mesh voltage with rod length

\begin{tabular}{|l|l|l|l|l|}
\hline $\begin{array}{l}\text { Rod } \\
\text { length } \\
(\mathrm{m})\end{array}$ & \multicolumn{2}{|c|}{ case $: 1$} & case:2 \\
\cline { 2 - 5 } & $\operatorname{Rg} \Omega)$ & $\mathrm{E}_{\mathrm{m}}(\mathrm{V})$ & $\operatorname{Rg} \Omega)$ & $\mathrm{E}_{\mathrm{m}}(\mathrm{V})$ \\
\hline 00 & 2.007 & 141.6 & 3.922 & 944.85 \\
\hline 3 & 1.937 & 87.00 & 3.443 & 569.42 \\
\hline 6 & 1.865 & 70.40 & 2.21 & 324.40 \\
\hline 9 & 1.853 & 66.94 & 0.908 & 87.44 \\
\hline
\end{tabular}




\begin{tabular}{|l|l|l|l|l|}
\hline 12 & 1.831 & 64.72 & 0.683 & 52.55 \\
\hline 15 & 1.803 & 62.10 & 0.577 & 38.38 \\
\hline
\end{tabular}

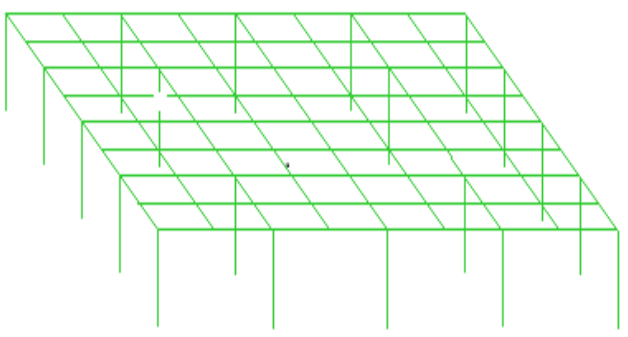

Fig. 7 Grid with rods for $\mathrm{S}_{4}$

\subsection{Grid Resistance and Mesh Voltage}

For negative value of K, ground rods are used very much profitably [19-20].the decrease in $\mathrm{Rg}$ and $\mathrm{Em}$ is at faster rate when rod length increase. Both $\mathrm{Rg}$ and Em decreases drastically when ground rod length increases more than top layer height, because most of the grid current is discharged into deep low resistivity soil [21-22].

For positive value of $\mathrm{K}$, Effect of increasing length of ground rod for decreasing $\mathrm{Rg}$ and $\mathrm{Em}$ is comparatively less. However, it is advantageneous to use ground rods of length up to the depth of low resistivity layer. For rod length more than $6 \mathrm{~m}$, both Rg and Em remains almost constant.

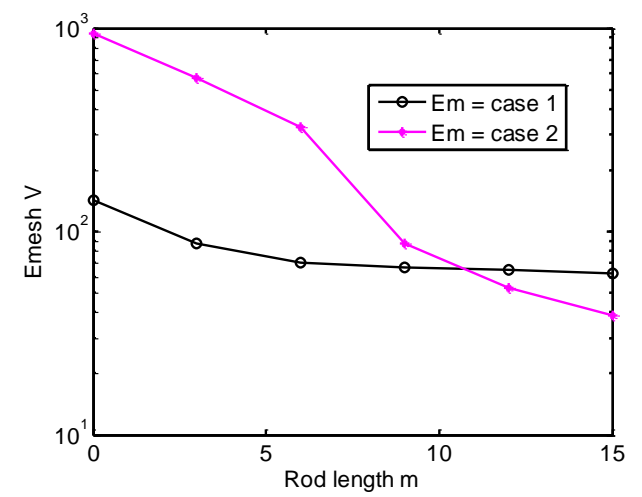

Fig. 8 Variation of mesh voltage with rod length

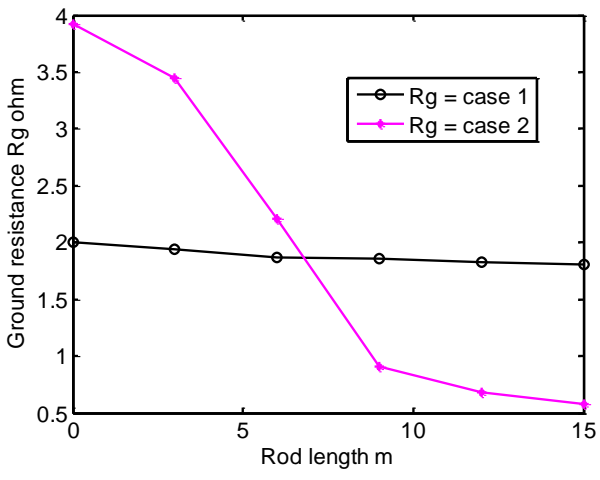

Fig. 9 Variation of grid resistance $\mathrm{Rg}$ with rod length

\section{RESUlTS AND DISCUSSIONS}

Simulation result are tabulated and displayed graphically shows that

- For the two layer soil model having higher soil resistivity at top layer \& lower resistivity at bottom layer, increase in grid depth decreases the mesh voltage, step voltage, grid resistance \& GPR which enhance the safety of operating person

- As soon as grid depth reaches to boundary of two soil layers, there is an abrupt decrease in mesh voltage, step voltage, grid resistance and GPR for case 2

- The phenomenon is reverse in case 1 .

- When the grid depth becomes more than equivalent radius of the grid, the grid resistance becomes almost constant.

- The increase in number of meshes and use of ground rods of varying length with horizontal grid makes the surface potential distribution more favorable for the personal safety and also 
decreases the grid resistance and ground potential rise which enhances the reliability of controlling devices.

\section{CONCLUSION}

The simulation of grid having different configuration is extensively carried out to evaluate the various parameters of grounding. It has great significance in design and analysis of substation grounding. For two layer soil model, having top layer resistivity higher than that of bottom layer, when depth of grid reaches to boundary of two soil layers, there is an abrupt decrease in mesh voltage, grid resistance and GPR.

The study also reveals that use of more number of meshes and ground rods which penetrates to low resistivity soil, decreases the mesh voltage, step voltage and GPR which thereby enhances the safety of person and reliability of controlling devices.Effect of shape and configuration of rods needs to be evaluated as a part of future scope of work.

\section{References}

[1]. ANSI/IEEE Std,80-2000,"Guide for Safety in AC Substation Grounding”,IEEE, New Yark.

[2]. F. P. Dawalibi and D. Mukhedkar, "Parametric Analysis of Grounding Grid", IEEE Trans. on PAS Vol.98 No. 5 Sep.-Oct. 1979 Pp. 1659-1668

[3]. Manul on," Earthing of A C Power Systems,"Publication No 302, C.B.I.P. New Delhi,Oct. 2007

[4]. I.S.3043-1987, Indian Standard Code of Practice for Earthing.

[5]. F P Dawalibi, J Ma, R D Southey," Behaviar of Grounding System in Multilayer Soils: A Parametric Analysis “,IEEE Trans. PWRD vol.9, No 1, Jan. 1994.Pp.333-342

[6]. F. P. Dawalibi and D. Mukhedkar," Optimum Design of Substation Grounding in Two layer Earth Structure",IEEE Trans.on PAS vol 94, No. 2,March- April 1975, Part II,Pg. 262-266

[7]. F. P. Dawalibi and D. Mukhedkar," Optimum Design of Substation Grounding in Two layer Earth Structure",IEEE Trans.on PAS vol 94, No. 2,March- April 1975, Part III, Pg. 267-272

[8]. E.T.B.Gross, B.V. Chitnis, L.S. Stratton,"'Grounding Grid for High Voltage Stations”, IEEE Trans. on PAS Vol.72 Part III, Aug.1953 Pg. 799-810

[9]. P. J. Lagace, J. Fortin, and E. D. Crainic, "Interpretation of resistivity grounding measurement in Nlayer soil using electrostatic images," IEEE Trans. Power Del., vol. 11, no. 3, pp. 1349-1354, Jul. 1996.

[10]. I. F. Gonos and I. A. Stathopulos, "Estimation of multilayer soil parameters using genetic algorithms,” IEEE Trans. Power Del., vol. 20,no. 1, pp. 100-106, Jan. 2005.

[11]. B.Thapar, V. Gerez, Balakrishnan, Donald A. Blank, "Simplified Equations For Mesh And Step Voltages In An Ac Substation”, , IEEE Transactions On Power Delivery Vol. 6, No. 2. April 1991 pp 601-607

[12]. Puttarach, N. Chakpitak, T. Kasirawat and C. Pongsriwat, ISubstation Grounding Grid Analysis with the Variation of Soil Layer Depth Method," IEEE PES International Conference PowerTech, Lausanne, Switzerland, pp.1881-1886, July, 2007.

[13]. Att Phayomhom, Somporn Sirisumrannukul, Tirapong Kasirawat, and Arwut Puttarach," Safety Design Planning of Ground Grid for Outdoor Substations in MEA's Power distribution system”, ECTI TRANSACTIONS ON ELECTRICAL ENG., ELECTRONICS, AND COMMUNICATIONS VOL.9, no.1 february 2011 pg.101-112

[14]. Laurent, P. G., "Les Bases Generales de la Technique des Mises a la Terre dans les Installations Electriques," Bulletin de la Societe Francaise des Electriciens, vol. 1, ser. 7, pp. 368402, July 1951.

[15]. Sverak, J. G., “Optimized grounding grid design using variable spacing technique,” IEEE Transactions on Power Apparatus and Systems, vol. PAS-95, no. 1, pp. 362-374, Jan./Feb. 1976.

[16]. Schwarz, S. J., "Analytical expression for resistance of grounding systems," AIEE Transactions on Power Apparatus and Systems, vol. 73, no. 13, part III-B, pp. 1011- 1016, Aug. 1954.

[17]. Y.L. Chow, M.M.A. Salama, "A Simplified Method For Calculating The Substation Grounding Grid Resistance”, , IEEE Transactions On Power Delivery, Vol. 9, No. 2.

[18]. G. F. Tagg, "Earth Resistances", George Newnes Ltd.,London 1964 (book).

[19]. J.K.Arora," Economic Design of Earth Electrode- A case study ", CBIP National Seminar on ,’Design of Earthing Systems”, 18-19 Dec-2003,CBIP, New Delhi, Pg.III-16-21 
[20]. J.K.Arora," Importance of Vertical Earth Electrodes in Earthig Design", CBIP Seminar on ,'Earthing Systems", May-2008, New Delhi, Pg.81-87

[21]. $\quad$ F. Dawalibi, D. Mukhedkar, "Influence of Ground Rods on Grounding Grids", IEEE Transactions on PAS, Vol. PAS-98,No. 6, November/December 1979, pp. 2089-2098.

[22]. How to--- engineering guide, "simple substation grounding grid analysis using Autogridpro,ses \& techonology. www.sestech.com

\section{Biography}

M.G. Unde is working as Professor in Electrical Engineering Deptt..at Pad. Dr. Vithalrao Vikhe Patil College of Engineering, Ahmednagar from last 24 years. He has completed his Graduate degree B.E. Elect. in 1986 from Government College of Engineering Pune and Masters Degree M.E. Power System in 1998 from the same College. His research interest is, power system analysis and power system grounding design and analysis.

B. E. Kushare had completed his Ph.D. in Power Quality from Pune University. He is Prof. \& Head of Electrical Engineering in K. K. Wagh Institute of Engg. Edu \& Research, Nashik. $\mathrm{He}$ is a Ph.D Guide of University of Pune. He has published about fifty research papers in various National ,International conferences and journals. He is certified energy auditor and power quality consultant. He is associated with various industries, National institutes and IITs
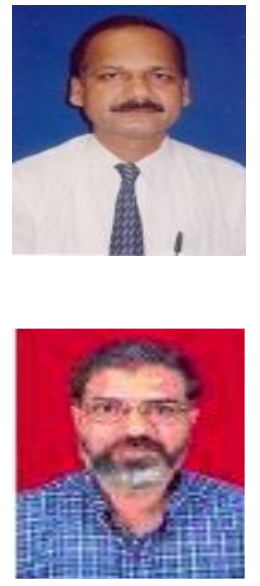